\title{
Скрытое студенческое недовольство в условиях академического капитализма: сравнительный анализ идеальных типов студентов гуманитарных и технических специальностей ${ }^{1,2}$
}

\author{
А.В. РЕЗАЕВ*, М.Л. НИ**
}

\begin{abstract}
*Андрей Владимирович Резаев - доктор философских наук, профессор, заведующий кафедрой сравнительной социологии, Санкт-Петербургский государственный университет. Адрес: 1999034, Санкт-Петербург, Университетская набережная, д. 7-9. E-mail: rezaev@hotmail.com

**Максим Леонидович Ни - аспирант кафедры сравнительной социологии, Санкт-Петербургский государственный университет. Адрес: 1999034, Санкт-Петербург, Университетская набережная, д. 7-9. E-mail: jintae@mail.ru

Цитирование: Резаев А.В., Ни М.Л. (2020) Скрытое студенческое недовольство в условиях академического капитализма: сравнительный анализ идеальных типов студентов гуманитарных и технических специальностей // Мир России. Т. 29. № 2. С. 49-71. DOI: $10.17323 / 1811-038 X-2020-29-2-49-71$
\end{abstract}

Цель настоящей статьи состоит в предложении конщептуальных инструментов для исследования скрытых (не вынесенных в публичное пространство) причин недовольства студентов вузов различными аспектами получаемого образования и в применении этих инструментов при анализе конкретных эмпирических кейсов. Рассмотрение скрытого недовольства студентов принципиально важно в контексте проникновения в практику управления вузами парадигмы академического капитализма, в рамках которой постулируется, с одной сторонь, ориентация на нуждьл студента, с другой сторонь, необходимость связи получаемого образования с требованиями современного рынка труда. Эмпирическим материалом для анализа выступают интервью и фокус-группы со студентами и преподавателями трех крупных вузов России и Украины, специализирующимися по социально-гуманитарным и техническим направлениям. В качестве основной теоретической базы были избраны положения французской прагматической социологии, в рамках которой университет рассматривается как организация, конституированная моральными

\footnotetext{
1 Исследование выполнено в рамках гранта РФФИ 17-33-00040-ОГН.

2 Статья опубликована в рамках проекта НИУ ВШЭ по поддержке публикаций авторов российских образовательных и научных организаций «Университетское партнерство».
} 
конвенциями между ее членами. Сравнительный анализ позволил выделить изенностные основания критических аргументов, высказываемых студентами относительно получаемого образования: в ситуациях недовольства студенты, как правило, апеллируют к миру иеенностей индустриального града справедливости (в терминологии Л. Болтански и Л. Тевено). На основании собранных данных мы выделяем два «идеальных» типа скрытого студенческого недовольства, принимающего сходные формы, однако сильно различающиеся по своей внутренней логике в зависимости от специальности. Представленные «идеальные» типь могут быть использованы в качестве оснований для гипотез в исследованиях российского (и шире - постсоветского) высшего образования.

Ключевые слова: университет, академический капитализм, недовольство, студенты, рынок труда, грады оправдания

\section{Постановка проблемы}

Проблемы и противоречия современного мира все отчетливее выявляют необходимость поиска путей наиболее рационального использования потенциала, которым обладает современное студенчество, что в свою очередь предполагает осознание и утверждение новых институциональных и структурных характеристик академии как таковой. В условиях трансформации системы высшего образования студент более не воспринимается исключительно как объект образовательной деятельности. Повышается доля участия обучающихся в процессах управления деятельностью вузов - повсеместно распространяются практики учета субъективного мнения студентов относительно получаемого образования. Однако, на наш взгляд, мониторинговые обследования, при их безусловной важности и необходимости, не позволяют в полной мере определить «болевые точки» студенческого опыта. В настоящей работе предлагается ряд концептуальных инструментов, позволяющих, во-первых, выйти за пределы дихотомии «субъект-объект» при анализе положения студентов в вузе, во-вторых, определить скрытые (не вынесенные в публичное пространство) мотивы недовольства обучающихся различными аспектами получаемого образования. Кроме того, мы постараемся продемонстрировать применимость подхода для эмпирического анализа.

Статья организована вокруг попытки ответа на несколько вопросов: существует ли скрытое недовольство студентов вузов по отношению к получаемому образованию; если да, то чем именно недовольны студенты и каковы основания критических аргументов; если существует скрытое недовольство, то по каким причинам оно не проявляется вовне и существует в форме «итальянской забастовки», когда внутреннее напряжение не выходит на поверхность; и каким образом получаемая специальность (точнее, предполагаемые перспективы трудоустройства, с ней связанные) влияет на характер проявления студенческого недовольства? Для ответа на поставленные вопросы были проанализированы результаты фокус-групп и интервью с профессорско-преподавательским составом и студентами социального-гуманитарных и технических специальностей трех крупных вузов России и Украины.

В России активное выражение недовольства со стороны студентов фиксируется достаточно редко. Приведем два наиболее ярких примера студенческой 
активности, направленной на реорганизацию учебного процесса и обсуждавшейся в публичном поле. Во-первых, это протесты ОД-групп на социологическом факультете МГУ в 2006-2008 гг. ${ }^{3}$, когда студенты высказывали недовольство радикальной идеологизированностью и отрывом от актуальных трендов программы обучения. Во-вторых, это недавние дискуссии на факультете гуманитарных наук НИУ ВШЭ, поводом для которых послужило общее недовольство студентов завышенными требованиями по вводному математическому курсу для будущих обладателей степеней по философии ${ }^{4}$. В обоих случаях аргументация студентов подкреплялась тезисом о безусловной необходимости следования духу академических свобод, а также проблематизацией релевантности учебного плана для нужд получаемой профессии. Студенты позиционировали себя как равноправные участники учебного процесса, мнение которых должно быть услышано и учтено. Однако подобные эпизоды остаются весьма редкими, и поэтому привлекают внимание общественности.

Возникновение у студентов недовольства, как правило, связано с формированием представления (отчетливого или неявного) о том, что должен знать и уметь специалист в избранной им области. Оставляя за рамками статьи идеологические мотивы академического сопротивления слушателей столичных вузов, мы хотели бы поставить вопрос о наличии скрытого недовольства в студенческой среде и о возможности активного действия студентов в более общей перспективе. Но прежде чем перейти к аналитической части, представляется необходимым описать общую ситуацию, сложившуюся в сфере высшего образования на сегодняшний день.

\section{Высшее образование в «мире текучей современности»}

Согласно метафоре Зигмунда Баумана, нам представилась возможность жить в мире «текучей современности», где текучесть подразумевает размывание национальных границ, переопределение целей и функций традиционных институтов вплоть до их отмирания, ускорение социокультурных изменений, а также пребывание всех сущностей в ситуации неопределенности, которая до этого была свойственна лишь рыночной деятельности. Очевидно, что высшее образование является одним из самых симптоматичных примеров, в котором проявляются «эффекты текучести». До сих пор перспектива получения диплома о высшем образовании рассматривается на обыденном уровне как важный элемент гаранта успешной жизни [Константиновский, Попова 2016, с. 8]. Между тем исследователи констатируют несколько иную тенденцию. Требования работодателей меняются с такой скоростью, что академическая подготовка просто не в состоянии обеспечить выпускников знаниями и навыками, необходимыми для немедленного выхода на рынок труда. В частности, эксперты Всемирного банка и НИУ ВШЭ отмечают две основные тенденции в развитии отечественной системы высшего образования - тотальная массовизация и

\footnotetext{
3 Инициативная группа соцфака МГУ «OD GROUP» (2007-2008) // Хроники студенческого самоуправления МГУ // https://chronicles.igmsu.org/odgroup/

4 Арамян А. (2017) Не геометр да не войдет? // DOXA. 6 марта 2017 // http://doxajournal.ru/uni/math
} 
развитие образования «исходя из самого себя» ${ }^{5}$. Другими словами, высшее образование описывается как автореферентная система, имеющая выход либо на нужды государственного заказа, либо на собственное воспроизводство. Такого рода капсулирование представляет собой эффект институциональной колеи, унаследованной от советской образовательной системы, что, по мнению исследователей, приводит к неадекватному воспроизводству профессиональных кадров, ориентированных на узкую специализацию и академизм. Между тем рыночная экономика требует от соискателей дополнительного набора навыков, среди которых эксперты особо выделяют способность к командной работе и принятию нестандартных решений. Подобного рода образовательный разрыв указывается в числе одного из основных факторов попадания выпускников вузов в категорию NEET (молодых людей, которые не учатся, не работают и не участвуют в профессиональной подготовке) [Гимпельсон, Капелюшников, Рощин 2017, с. 129].

Кроме того, и сама академия испытывает на себе эффекты социального ускорения. Если раньше основным делом университетского преподавателя было преподавание и исследования, то сейчас появляются жесткие требования к обязательному числу публикаций за отчетный период, привлечению стороннего финансирования, участию в определенном количестве конференций и т.д. [Абрамов 2011]. Одновременно с этим образовательная политика выдвигает тезис о том, что обучение должно быть эффективным, служащим интеграции студентов в экономическую и общественную структуру местных и национальных сообществ [Двенадцать решений для нового образования 2018, с. 58].

В поле исследований высшего образования процессы адаптации вуза к социальным изменениям наиболее полно были проанализированы Ш. Слотер и Л. Лесли, результатом работы которых стала концепция академического капитализма [Slaughter, Leslie 1997]. Описание данного феномена начинается с краткого экскурса в экономическую историю. Вплоть до 1970-х гг. автономия университетов ${ }^{6}$ в США и ряде стран Западной Европы основывалась на представлениях об образовании как форме общественного блага, что позволяло преподавательскому составу занимать дистанцию по отношению к требованиям рынка. Статус выпускника университета был ценен сам по себе и повышал шансы на трудоустройство. Период начала 1970-х гг. ознаменовался коренной трансформацией мирового экономического устройства. Традиционно считавшиеся особенно ценными и значимыми природные ресурсы и продукты ручного труда уступили пальму первенства интеллектуальным способностям и прикладным навыкам, применяемым для скорейшего производства инноваций. Обновленные условия функционирования рынка сейчас принято называть «экономикой знаний» [Нефедова 2015]. Н. Штер выдвигает и развивает тезис о том, что в современном мире знание становится важнейшим источником развития капиталистических экономик, что радикально изменяет не только саму экономику, но и наши подходы к ее исследованию [Stehr 2002].

Экономика знаний связывается с ускорением и усложнением экономических и политических процессов. Возвращаясь к метафоре 3. Баумана, экономика и политика становятся «текучими» поверх границ национальных государств, то есть

\footnotetext{
5 Российское образование не ориентируется на рынок труда (2013) // НИУ ВШЭ. 28 мая 2013 // https://iq.hse.ru/news/177669944.html

6 Здесь идет речь о Гумбольдтовской модели исследовательского университета [Шнедельбах 2002].
} 
наступает период глобализации, что для академической жизни означает радикальные эффекты сближения, которое, во-первых, подразумевает усиление обмена успешным опытом организации образовательного процесса и исследовательской деятельности [Нефедова 2015, с. 75], а во-вторых, консолидацию с общей логикой рыночной экономики как в области требований рынка труда, так и внедрения результатов научной деятельности во внешнюю среду [Hess 2007]. Из духа глобализации, согласно Ш. Слотер и Л. Лесли, рождается академический капитализм, выраженный в сокращении свободного финансирования университетов в пользу фокусированных, выгодных с точки зрения рынка вливаний, иначе говоря, меняются конвенции. Университеты теперь поставлены в режим жесткой экономии; сотрудники вынуждены вести свою работу, не только и не столько ориентируясь на свободный поиск научной истины, сколько отталкиваясь от условий внешнего финансирования $^{7}$ - государственных исследовательских грантов, средств из фондов промышленного сектора, создания научных парков, доступных для пользования внешними заказчиками, а также привлечения большего числа студентов ${ }^{8}$.

Концепция академического капитализма описывает тенденцию копирования вузами формы организации, подобной рынку, что подразумевает весь арсенал маркетинговых и менеджералистских стратегий для привлечения ресурсов, необходимых как для функционирования университета в целом, так и для нужд отдельных департаментов или исследовательских центров. Обращение к отечественным публикациям, посвященным проблеме академического капитализма, показывает, что чаще всего предметом анализа становятся две темы: организационные изменения структуры университетов [Стариков 2016; Соколов 2017]; положение преподавателя/исследователя в новых условиях [Абрамов 2011; Абрамов 2016]. Вопрос о роли студента в сложившемся контексте академической жизни рассматривается либо с точки зрения менеджералистской практики, либо с точки зрения жизненных траекторий после выпуска [Малик, Куракин, Павленко 2018]. Первое направление подразумевает процессуальную логику, учет студенческой перспективы как во время, так и по окончании обучения. Здесь лейтмотивом становится определение наиболее продуктивной метафоры, характеризующей роль студента в рыночно-ориентированной модели университетов. Так, Феликс Мориндж рассматривает возможности и ограничения метафоры «студент как клиент» в контексте трансформации высшего образования [Maringe 2011]. В свою очередь Малькольм Тайт критикует весь спектр метафор студента, основанный на логике свободных рыночных отношений. Исследователь постулирует их неадекватность складывающемуся положению дел и в противовес метафорам клиента, потребителя и соучастника предлагает метафору студента как пешки (pawn), не имеющей никакого веса в организации образовательного

\footnotetext{
7 Естественно, подобное положение дел не устраивает университетских сотрудников [Гилл 2014], что выливается в ностальгические рассуждения о «старом добром» университете. В этом плане интересно замечание Стива Фуллера о том, что бурный рост финансирования академии в период расцвета социального государства основывался на принципе полезности высшего образования для процветания граждан как в смысле повышения перспектив для выхода на рынок труда, так и в плане разработок потенциально полезных для общества продуктов. Тот же принцип является драйвером финансирования и сегодня, но на более частном уровне [Фуллер 2018, с. 40].

8 Здесь имеются в виду студенты, готовые платить за обучение, но данную логику можно распространить и на студентов, обучающихся за счет средств государственного бюджета, так как высокая популярность учебного заведения увеличивает вероятность более щедрого государственного финансирования.
} 
процесса [Tight 2013]. Тем не менее, если высшее образование копирует рыночно-ориентированные формы организации и студенчество перестает быть простым объектом образовательной политики, то у данной группы появляется потенциальная возможность влиять на ход образовательного процесса, выстраивать свое обучение таким образом, чтобы иметь максимальное преимущество на рынке труда. В этом отношении метафора «пешки» представляется не вполне верной. И прежде чем применять к образовательной политике метафоры студента как клиента [Furedi 2011, p. 4] или студента как соучастника производства знаний, необходимы анализ потенциальной способности студенчества публично отстаивать свое право на участие в управление вузом ${ }^{9}$ и исследование механизмов, препятствующих артикуляции недовольства.

\section{Теоретическая рамка: университет как организация, конституированная моральными компромиссами}

Эпоха академического капитализма ставит современных исследователей перед необходимостью поиска новых теорий и методологий для анализа социальных процессов в вузах. Классические для социологии образования структурно-функциональный и конфликтологические подходы [Старыгина 2016] предполагают статичную модель образовательных институций. Университет здесь имеет строго определенные функции и цели, ограниченные, во-первых, четко артикулированными требованиями рынка труда, во-вторых, государственным заказом. В свою очередь, академический капитализм ${ }^{10}$ подразумевает, что высшее образование более не синхронизировано с внешним миром. Теперь академия вынуждена вовлекаться в рыночную логику на общих правах и сталкиваться с ситуацией рыночной неопределенности и скорости изменений. Отсюда вытекают описанные выше подходы, в рамках которых кооперация схемы взаимодействия расширяется: в корректировку программ обучения включаются не только традиционные акторы - администрация вуза, работодатели и государство, но и студенты. Таким образом, интерпретация недовольства как рассогласования между идеальным и наличным является нерелевантной, так как идеальное находится в постоянной трансформации.

Рыночный характер взаимодействий в системе высшего образования подсказывает, что продуктивным ходом будет обращение к ресурсам экономической теории, благодаря которой появляется возможность понять стратегии поведения современных университетов, опираясь на теорию рационального выбора и конкуренции за ресурсы. С другой стороны, обращение к экономическому подходу

9 Под «публичностью» мы понимаем анонсирование недовольства различными аспектами высшего образования, артикулированные и вынесенные на всеобее обозрение как в рамках вуза, так и шире - через обращение к СМИ. В образовательных организациях механизмы опубличивания могут предполагать широкий спектр возможностей: выражение мнений через регулярные институциональные опросы, написание коллективных петиций, внесение интересующей повестки в качестве темы для обсуждения в рамках научных советов и т.п.

10 Академический капитализм - это, прежде всего, характеристика современных условий функционирования системы высшего образования и только, во-вторых - теоретический подход. 
смещает зону анализа в сторону институционального взаимодействия, оставляя за бортом сложную машинерию социальных отношений внутри университета как организации. В таком случае необходима более гибкая концептуальная схема, фокусирующая внимание и на логике работы институтов, и на индивидуальном действии.

Отталкиваясь от приведенных выше рассуждений, авторами было принято решение воспользоваться теоретическими ресурсами французской прагматической социологии, разработанной Лораном Тевено и Люком Болтански. Ключевой особенностью данного подхода является внимание к критическим суждениям акторов [Болтански, Тевено 2013, с. 35]. В отличие от социологических подходов, наследующих структурно-функциональный анализ, Л. Тевено и Л. Болтански предлагают такой образ социальной реальности, в котором социальный порядок не подчинен единому нормативному императиву. Коллективы и организации, внешне представляющиеся монолитными, становятся результатом компромиссов между различными способами обоснования лучшего и справедливого способа коллективной деятельности. Под обоснованием понимается процесс выдвижения критических суждений в спорных ситуациях. Спор высвечивает чувство несправедливости по отношению к наличному положению дел и выявляет идеальные, с точки зрения противоборствующих сторон, модели порядка. Отсюда проистекает важный момент: критические суждения становятся легитимными и подлежащими учету только в том случае, если они основаны на ценностном благе, потенциально справедливом, общем для всего коллектива ${ }^{11}$. Обобщенные ценностные блага обозначаются как грады (cite), или миры справедливости [Болтански, Тевено 2013, с. 42], каждому из которых соответствует собственный справедливый порядок (ordre de justice), или порядок величия. Под порядком величия подразумевается способ оценки и упорядочивания элементов реальности по специализированным моральным критериям. Кроме того, каждому граду соответствуют особые формы проявления значимого качества.

Л. Тевено и Л. Болтански выделяют грады справедливости на основании принципов сосуществования людей, выраженных в трудах классиков моральной философии, а также в пособиях по менеджменту. Предполагается, что данные принципы находят свое выражение в обыденных суждениях членов современных обществ, что позволяет фиксировать их эмпирически. В своих ранних работах авторы выделяют всего шесть миров справедливости, но подчеркивают, что это количество не фиксировано и может пополняться. Для удобства мы позаимствуем таблицу описания градов из работы О.В. Ковеневой [Ковенева 2008, с. 11] (таблицьа 1).

\footnotetext{
11 Коллектив рассматривается здесь как гетерогенная сущность. Легитимация через опубличивание это попытка одной из частей коллектива сделать свою точку зрения доминирующей. Даже если усилия акторов увенчаются успехом, это не отменяет существования групп с радикально иными ценностными суждениями об «общем» благе. В таком контексте вуз рассматривается как коллектив, состоящий из администрации, профессорско-преподавательского состава, студентов, технического персонала и т.п. Каждая из категорий может иметь свое видение идеальной организации взаимодействий, необходимой для существования стабилизированного коллектива, выраженные в явной или скрытой критике по отношению к наличному положению дел. Более того, внутри каждой из категорий могут быть субкатегории, дифференцированные по ценностным основаниям критики.
} 


\section{Таблица 1. Модель градов справедливости}

\begin{tabular}{|c|c|c|c|}
\hline $\begin{array}{c}\text { Грады справедливости } \\
\text { / миры оценки }\end{array}$ & $\begin{array}{c}\text { Высший } \\
\text { общий принцип } \\
\text { («общее благо») }\end{array}$ & $\begin{array}{l}\text { Формы проявления } \\
\text { значимого качества }\end{array}$ & Философский труд \\
\hline Град / мир вдохновения & Вдохновение & $\begin{array}{c}\text { Творчество, } \\
\text { чувственность, } \\
\text { личностный порыв, } \\
\text { необычность, } \\
\text { спонтанность, } \\
\text { безудержность, } \\
\text { восприимчивость, } \\
\text { эмоциональность, } \\
\text { стихийность }\end{array}$ & $\begin{array}{c}\text { Блаженный Августин } \\
\text { «О Граде Божием» }\end{array}$ \\
\hline $\begin{array}{c}\text { Патриархальный град / } \\
\text { мир }\end{array}$ & $\begin{array}{c}\text { Триада Род - } \\
\text { Иерархия - Традиция }\end{array}$ & $\begin{array}{c}\text { Личное доверие, } \\
\text { тесные связи, } \\
\text { личная зависимость, } \\
\text { личное расположение, } \\
\text { лояльность, } \\
\text { иерархия, авторитет, } \\
\text { традиционность, } \\
\text { приверженность } \\
\text { прошлому }\end{array}$ & $\begin{array}{c}\text { Ж.-Б. Боссюэ } \\
\text { «Политика, из самих } \\
\text { слов Священного } \\
\text { Писания почерпнутая» }\end{array}$ \\
\hline Град / мир репутации & Репутация & $\begin{array}{c}\text { Известность, престиж, } \\
\text { именитость }\end{array}$ & $\begin{array}{c}\text { Т. Гоббс «Левиафан, или } \\
\text { Материя, форма и власть } \\
\text { государства церковного } \\
\text { и гражданского» }\end{array}$ \\
\hline Гражданский град / мир & Общая воля & $\begin{array}{c}\text { Коллективизм, } \\
\text { равенство, солидарность, } \\
\text { единение, законность }\end{array}$ & $\begin{array}{c}\text { Ж.-Ж. Руссо } \\
\text { «Об общественном } \\
\text { договоре» }\end{array}$ \\
\hline Рыночный град / мир & Конкуренция & $\begin{array}{c}\text { Цена, обмен, товарные } \\
\text { отношения }\end{array}$ & $\begin{array}{c}\text { А. Смит «Исследование } \\
\text { о природе и причинах } \\
\text { богатства народов» }\end{array}$ \\
\hline $\begin{array}{c}\text { Град / мир } \\
\text { индустриальный }\end{array}$ & Эффективность & $\begin{array}{c}\text { Производительность, } \\
\text { эффективность, } \\
\text { научность, единство } \\
\text { науки } \\
\text { и промышленности, } \\
\text { планирование }\end{array}$ & $\begin{array}{c}\text { К.А. Сен-Симон } \\
\text { «Организатор», } \\
\text { «О промышленной } \\
\text { системе», «Катехизис } \\
\text { промышленников» }\end{array}$ \\
\hline
\end{tabular}

Различия в общих благах делают взаимодействия между участниками коллективов проблематичными: ценности града вдохновения, например, вступают в прямое противоречие с ценностями индустриального града. Поэтому взаимодействия внутри коллективов отличаются наличием скрытого напряжения, в особенности в случаях столкновения принципиально разных логик. С другой стороны, между некоторыми градами справедливости может устанавливаться устойчивый и долгосрочный компромисс. Академический капитализм продуцирует такой способ существования вузов, который отвечает формам проявления как индустриального, так и рыночного града.

Как было отмечено выше, во французской прагматической социологии организация рассматривается как компромисс между различными градами обоснования справедливости. Каждый град стремится построить социальную организацию коллектива по своему образу. В связи с этим особый интерес представляет ди- 
намика взаимодействия между различными градами, что требует расширения исходной схемы анализа оправданий. Для этой цели мы обратимся к более поздним наработкам Л. Тевено, а именно к теории режимов вовлеченности, подразумевающей различные градации обобществления индивидуального действия с доступными ему элементами реальности и одновременно его обоснование с опорой на ту или иную форму блага. Степень обобществления специфицирует режимы вовлеченности в зависимости от способа интеграции окружающей среды в коллективе [Тевено 2002, с. 24]. В своих работах Л. Тевено выделяет разное количество режимов вовлеченности ${ }^{12}$, и мы остановимся лишь на трех базовых:

1) режим критики и оправдания, в рамках которого индивидуальное благо осознается как общезначимое для коллектива, что отстаивается в публичных спорах;

2) режим планового действия, предполагает выстраивание своих действий согласно заранее определенной цели и плану ее достижения; окружение расценивается как функциональный ресурс, отталкиваясь от которого выстраиваются долгосрочные стратегии достижения результата; ближайший эквивалент - модель рационального действия в экономической теории;

3) режим привычного пользования, или режим близости; данный режим предполагает действия, направленные на приспособление к окружению, и выстраивание личных доверительных отношений; здесь превыше всего ценится удобство, комфорт от пребывания в коллективе, забота и бережное внимание.

Из приведенной характеристики режимов видно, что два из них предполагают распространение модели градов на автономные части коллектива. В режиме планового действия это индивид, а в режиме близости - сообщество ${ }^{13}$ внутри организации. Таким образом, внутри коллектива не все акторы выводят критические суждения на публичный уровень. В режимах близости и индивидуального действия затруднения координации совместных действий решаются на локальном уровне и специфицированы апелляцией к менее унифицированным благам [Тевено 2009]. Тем не менее локальные споры имеют возможность перехода на публичный уровень, и такого рода ситуации могут возникнуть в том случае, когда общий порядок, принятый в организации, вторгается в зону действия режима близости или индивидуального действия. Появляющиеся в таком случае противоречия позволяют совершить ряд познавательных операций на пути к режиму критики и оправдания. Во-первых, индивид или группа осознают, что способ координации деятельности, принятый в организации, угрожает приватному режиму их деятельности и потенциально несправедлив для всего коллектива. Во-вторых, акторы вырабатывают необходимые суждения в защиту и обоснование своего способа действий. В-третьих, они взвешивают необходимость действий в приватном или публичном режимах [Тевено 2002, с. 26].

Исходя из представленных элементов прагматической социологии, мы выбираем базовую метафору для перевода проблемы скрытого недовольства студентов в концептуальные рамки. Университет мы представляем как организацию,

\footnotetext{
12 Например, в работе, посвященной анализу стилей теоретизирования в социальных науках, выделяется пять режимов [Тевено 2006].

13 В системе высшего образования это может быть конкретный департамент, кафедра, лаборатория или же просто группа, объединенная профессиональными и дружескими отношениями.
} 
координация деятельности которой выстраивается исходя из моральных конвенций между ее членами, и в этом случае студент уравнивается в правах управления университетом с другими акторами. Основной способ управления, доступный студенчеству, - это возможность выносить критические суждения по поводу качества образовательного процесса, которые проявляются как на уровне публичных высказываний, так и в форме локальных споров.

Отсылая к логике академического капитализма, мы формулируем гипотезу о том, что основным ориентиром критики будет несоответствие учебной программы и текущих требований рынка труда. Следовательно, в суждениях мы должны обнаружить маркеры индустриального града оправдания ${ }^{14}$, вдохновленные требованиями эффективности, планирования, соответствия теории практике и большего количества практически применимых программ и курсов. Та же модель критики может быть обнаружена в ретроспективных моментах выбора нынешним студентом специальности при поступлении в институт.

\section{Описание данных и методология анализа}

Прежде чем переходить к анализу зафиксированных случаев студенческого недовольства, следует отметить, что доступный нам массив данных определен исследовательским вопросом, отличающимся от нашего: изначально дизайн исследования, в рамках которого проходил сбор данных, предполагал поиск ответов на вопрос о механизмах возникновения этносоциальных конфликтов в высших учебных заведениях, опосредованных интенсивными миграционными потоками [Трегубова, Стариков 2017, с. 123]. Команда исследователей лаборатории «Транснационализм и миграционные процессы: сравнительный и институциональный анализ» в период с апреля по декабрь 2016 г. провела серию полуформализованных интервью и фокус-групп со студентами и преподавателями крупнейших вузов Казани, Ростова-на-Дону и Киева. Из полученного массива были отобраны расшифровки интервью и фокус-групп, в которых так или иначе возникала тема студенческого недовольства. Итоговая выборка получилась смещенной. В случае Украины был отобран лишь один город и один вуз - Киевский национальный университет им. Тараса Шевченко, в то время как для России было выбрано два вуза - Казанский федеральный университет и Южный федеральный университет (Ростов-наДону), в которых были отобраны случаи студентов бакалавриата и магистратуры, обучавшихся по следующим направлениям подготовки: кибернетика и бизнес-информатика (КНУ им. Тараса Шевченко), социология (ЮФУ, КНУ им. Тараса Шевченко) и зарубежное регионоведение (ЮФУ). Кроме того, релевантными для нас оказались интервью с преподавателями Института социально-философских наук и массовой коммуникации Казанского федерального университета (таблиц̧а 2).

\footnotetext{
14 Здесь может возникнуть вопрос, почему мы говорим об индустриальном, а не о проектном (сетевом) граде оправдания. Это справедливый вопрос, однако, из-за ограниченного объема материала, мы вынуждены вынести рассмотрение проектного града за рамки данной статьи. Рассмотрение проектного града потребовало бы анализа университетской политики, формирования образовательных программ, их соотнесения с требованиями Министерства образования и конкретных работодателей и т.п.
} 
Таблица 2. Структура и объем выборки

\begin{tabular}{|c|c|}
\hline Вуз & Выборка \\
\hline $\begin{array}{l}\text { Казанский федеральный университет } \\
\text { (Казань) }\end{array}$ & $\begin{array}{l}\text { Институт социально-философских наук и массовой коммуникации } \\
\text { • интервью с преподавателями }(\mathrm{N}=8) \\
\text { • интервью со студентами }(\mathrm{N}=7)\end{array}$ \\
\hline \multirow{2}{*}{$\begin{array}{l}\text { Киевский национальный университет } \\
\text { им. Тараса Шевченко (Киев) }\end{array}$} & $\begin{array}{l}\text { Факультет компьютерных наук и кибернетики: } \\
\text { • фокус-группа со студентами }(\mathrm{N}=5) \\
\text { • индивидуальные интервью со студентами }(\mathrm{N}=2)\end{array}$ \\
\hline & $\begin{array}{l}\text { Факультет социологии: } \\
\text { • фокус-группа со студентами (N=5) } \\
\text { • индивидуальные интервью со студентами }(\mathrm{N}=5) \\
\text { • интервью с преподавателями (N=5) }\end{array}$ \\
\hline $\begin{array}{l}\text { Южный федеральный университет } \\
\text { (Ростов-на-Дону) }\end{array}$ & $\begin{array}{l}\text { Институт социологии и регионоведения: } \\
\text { • интервью со студентами }(\mathrm{N}=12)\end{array}$ \\
\hline
\end{tabular}

Данные были подвергнуты процедурам индуктивного анализа посредством открытого и осевого кодирования [Страусс, Корбин 2001, с. 52]. Необходимо отметить, что авторам не удалось в полной мере охватить разнообразие репертуаров критики студентов обозначенных вузов и закрыть требование теоретического насыщения выборки [Страусс, Корбин 2001, с. 147]. Тем не менее представленных данных оказалось достаточно для того, чтобы получить предварительную картину и сформулировать ряд исследовательских предположений, на основании которых мы выделили два идеальных типа скрытого студенческого недовольства, которые могут быть положены в основание гипотез для последующих исследований ${ }^{15}$.

\section{Анализ данных: поиск моральных оснований студенческой критики}

В ходе работы мы ориентировались на поиск критики актуальных для информантов контекстов высшего образования с учетом эффектов академического капитализма. Далее мы попытаемся показать обнаруженные точки напряжения в виде обобщенной картины. При этом мы сохраняем сравнительную перспективу, но линия разделения кейсов в нашем исследовании продиктована не территориальным статусом университетов (по крайней мере, в первом приближении), а специализацией информантов. Как будет продемонстрировано далее, существуют серьезные

\footnotetext{
15 Согласно характеристике Макса Вебера, идеальный тип «создается посредством одностороннего усиления одной или нескольких точек зрения и соединения множества диффузно и дискретно существующих единичных явлений (в одном случае их может быть больше, в другом - меньше, а кое-где они вообще отсутствуют), которые соответствуют тем односторонне вычлененным точкам зрения и складываются в единый мысленный образ» [Вебер 1990, с. 389]. Мы следуем за определением классика: сконструированные в настоящем исследовании идеальные типы обладают концептуальной целостностью, единством и могут выступать в качестве ориентиров для проверки/критики в исследованиях студенческой мотивации, взаимоотношений между академией и рынком труда, трансформации образовательных практик, формирования недовольства и протестной активности в академии и др.
} 
различия между критикой системы высшего образования со стороны студентов технического профиля, с одной стороны, и социально-гуманитарных специальностей, с другой.

В интервью со студентами обнаружилось два относительно устойчивых паттерна, которые мы определили как «туман войны» и «область плотности смыслов». Метафора «туман войны» позаимствована из военной теории Карла фон Клаузевица [Клаузевиц 2009, с. 80]. По мысли автора, театр военных действий представляет собой область недостоверного и изменчивого, и полководцы всегда находятся в ситуации недостаточности данных, их первоначальные планы сталкиваются с совершенно иным положением вещей по сравнению с первоначальными ожиданиями. Поэтому для успеха в военной кампании участникам необходимо быть опытными тактиками и уметь оперативно менять исходный план действий. Что получается при переносе военной логики в ситуацию получения высшего образования? При поступлении в вуз студент занимает место полководца, перед ним так или иначе возникает стратегическая цель, определенная вопросом: что я смогу сделать, обладая знаниями и навыками по выбранной специальности? Обычно ответ находится в пестрых рекламных буклетах, описывающих достоинства обучения на образовательной программе X, или в образе специалиста, растиражированного в массовой культуре ${ }^{16}$, или в описаниях знакомых и т.д. В общем, у абитуриента должен быть сформирован образ социального объекта («будущая специальность»), но степень его определенности всегда различается: данных всегда недостаточно, в процессе обучения студенты с разным успехом занимаются уточнением того, чем же им предстоит заниматься и что же они изучают. Одни студенты обладают большим количеством ресурсов для профессиональной идентификации ${ }^{17}$, другие - меньшим. Это два противоположных полюса определения ситуации, и отсюда возникает вторая метафора - «области плотности смыслов», заимствованная нами из работ Дэвида Гребера [Graeber 2012]. Это ситуация, полностью противоположная «туману войны». Ее можно представить как ориентирование на местности с точной картой или инструкцией на руках ${ }^{18}$, руководствуясь которой индивид оперативно определяет актуальное знание как релевантное или нерелевантное воображаемому образу профессии и перспективам на рынке труда.

В доступных нам интервью прослеживается достаточно четкая групповая граница, определяющая тех, кто обладает большими и меньшими ресурсами профессиональной идентификации. Мы начнем с описания суждений студентов социально-гуманитарного профиля («социология» и «зарубежное регионоведение»). Географическая принадлежность не играет существенной роли, поэтому мы будем представлять данные в обобщенном виде без привязки к конкретному вузу или стране.

Для начала попытаемся проанализировать, какими мотивами руководствовались студенты социально-гуманитарных профилей при выборе специальности.

\footnotetext{
16 Например, существуют исследования, демонстрирующие прямое влияние сериала «Доктор Хаус» на популярность выбора медицинских специальностей в Америке [Hirt, Wong, Erichsen, White 2012].

17 Или деидентификации, когда приходит осознание того, что выбор образовательного трека был ошибкой.

18 Для этнометодологов, например, инструкция представляет собой способ сверки индексичных действий здесь-и-сейчас с описанием, зафиксированным в виде образа объекта. Инструкция и социальное действие не согласуются друг с другом на сто процентов, но снимают большую часть неопределенности [Lynch 2002].
} 
Чаще всего решение принималось без продуманной стратегии относительно перспектив на рынке труда. Студенты называют в качестве основных причин выбора образовательного направления новизну и необычность профессии (мир вдохновения), престиж университета (мир престижа), а также случайное совпадение обстоятельств.

\begin{abstract}
«Еще я руководствовалась тем, что общество у нас динамично развивается. И те специальности, которые всегда были популярными (экономисты, юристы), ими рынок будет перенасыщен. Значит, надо идти в ногу со временем и выбирать специальность, которая развивается и будет популярной. И мне показалось, что социиология - это как раз такая специильность. Мне казалось престижным, если ты скажешь, что ты по образованию сочиолог, а тебя спросят: “Социолог - это социальный работник?”. Никто об этом не слымал, и поэтому я хотела именно сюда. Это что-то новое, и в будущем будет полезно» (студент-социолог).

«Про специальность я узнал незадолго до окончания школьы. Мне подходили предметь ЕГЭ» (студент-социолог).

«У нас есть такая тендениия: я хотел в КНУ, но не поступил, поэтому социология» (студент-социолог).
\end{abstract}

Несмотря на то, что приведенные фрагменты взяты из интервью со студентами-социологами, в целом подобная аргументация справедлива и для попавших в выборку регионоведов. Отсутствие инструктивного знания по поводу предполагаемой профессии подталкивает к альтернативным способам обоснования рациональности решения. Здесь возникает вопрос: если студент заранее не знал, куда может пойти работать социолог или регионовед и какие знания и навыки имеют решающее значения для успешного трудоустройства по специальности, то каким образом в таком случае могут появиться ресурсы для критики?

Недовольство в отношении образовательной программы обычно появляется уже в начале обучения. Критикуется, собственно, не качество отдельных курсов или работа отдельных преподавателей, а связность программы обучения в целом, и особенно явно это видно на примере социологов. Студенты находят дезориентирующей ситуацию, когда в рамках отдельных курсов предметная деятельность социолога описывается по-разному.

\footnotetext{
«Почему нам не нравится? Mbl, наверное, не видим перспектив. Нам никто толком не объяснил, чему мы именно учимся» (студент-социолог).

«Они [студенты] разочарованы тем, что не понимают, что такое сочиология. И еще организация образования - это полный хаос» (студент-социолог).
}

Новые данные о профессии не столько делают ситуацию более осмысленной, сколько вносят сумятицу и оставляют ощущение аморфности, что не приближает их к рассеиванию «тумана войны». Интересно, что студенты, обучающиеся по специальности «зарубежное регионоведение», настроены по отношению к качеству 
высшего образования менее критично, но, с другой стороны, ощущение неопределенности им также присуще.

\begin{abstract}
«Mbl - регионоведы. Конкретной специильности у нас нет. Мы долюны быть готовы к самым разнылм ситуачиям. И мои друзья как раз очень подходят для этой специальности» (студент-регионовед).

«У нас, конечно, интересно, но не совсем понятно, куда идти работать с таким дипломом» (студент-регионовед).
\end{abstract}

В случае студентов-социологов прослеживается иерархия специализаций внутри дисциплины. Относительно перспектив на рынке труда ценятся знания в области проведения прикладных количественных исследований. В отличие от абстрактной теории, методы и вообще «магия цифр» видятся как большое преимущество для будущего трудоустройства.

«Есть такое, что самая классная кафедра - методов. Многие идут туда, плюс это связано с методами, соответственно, у всех возникают ожидания, что вот, научусь быть крутым пользователем SPSS. Приду, всем все посчитаю, и работы в этой сфере будет больше, чем на теории и истории. Плюс считается, что теория - о, боже, что это такое? И ничего, кроме Дюркгейма, здесь не напишешь. На эту кафедру идут, если можно так сказать, все, кто не определился с кафедрами до этого, либо те, кто стабильно и уверенно решил заниматься теорией» (студент-социолог).

Однако же информации о возможных сферах применения данных навыков у студентов нет, о чем свидетельствует неуверенность в перспективах на рынке труда.

«Студенты хотят работать в больших международных компаниях. Заниматься каким-то маркетингом, какими-то политическими исследованиями, $H R, P R-$ точно не знаю. Вообще, как выйдет» (студент-социолог).

Критика различных аспектов получения высшего образования со стороны студентов социально-гуманитарного профиля ${ }^{19}$, как и предполагалось, существует и опирается на аргументы индустриального града с его требованиями к четкости, эффективности и планированию. Однако недовольство не переводится на уровень публичных споров ввиду неспособности студентов четко сформулировать, какие именно навыки и знания в рамках специализации могут повысить шансы успешной

19 Стоит оговориться, что, скажем, для экономистов и юристов перспективы рынка труда выглядят если не более радужными, то хотя бы более определенными с точки зрения совпадения специальности в дипломе и названия вакансии. 
интеграции на рынке труда. В случае студентов-социологов предполагается, что полезным знанием окажутся навыки прикладных количественных исследований, но представления о том, где именно и в какой степени они окажутся практически применимыми, выглядят размытыми. Вероятно, для регионоведов подобным потенциально ценным ресурсом является знание языка изучаемого региона, но в силу дефицита данных оставим этот вопрос на будущее.

Полное осознание релевантности осваиваемых знаний и навыков характерно для студентов технического профиля обучения. В наибольшей степени это справедливо для представителей специальностей, так или иначе связанных с информационными технологиями (кибернетика и бизнес-информатика в кейсе КНУ им. Тараса Шевченко). В отличие от социологов и регионоведов, выбор профессии абитуриентами технических вузов чаще определяется прагматическими соображениями либо он является логичным следствием интереса к точным наукам и информационным технологиям, проявившимся еще в школьные годы.

«Я еще в школе начал программировать, писал простенький код, на олимпиады ездил» (студент-кибернетик).

«Суть кибернетики еще и в том, что ты можешь быть математиком, программистом, аналитиком, экономистом» (студент-кибернетик).

В этом плане интересным представляется тот факт, что многие студенты, связывающие свое будущее со сферой IT, обосновывают выбор профессии через апелляцию не только к ценностям индустриального и рыночного миров, но и к миру вдохновения.

«Приятно знать, что ты можешь изготовить свой продукт, кто-то будет им пользоваться и думать: “О! Как классно его написали. Как он классно выглядит. Какой у него классный функиионал”. Ну, он, возможно, и не будет знать, что ты его написал, но он будет получать от этого удовольствие, а ты будешь получать за это деньги, а это приятно» (студент-кибернетик).

Возвращаясь в исходное русло анализа, отметим, что следствием осознанного выбора специальности является четкая профессиональная идентификация, что подкрепляется возможностью найти работу по специальности параллельно процессу обучения.

«Со второго-третьего курса люди уже находят работу. Ну, просто работу найти не так сложно. Рынок IТ Украины, конечно, меньше чем в Москве и Санкт-Петербурге, но у нас есть много филиалов компаний. Там все очень похоже на то, как все устроено там [в России]. Ты приходишь на собеседование, от тебя требуют какие-то практические и теоретические знания. Говоришь, что ты студент, и они дают тебе болееменее свободный график. И, в приничие, все можно успеть» (студент-кибернетик). 
Критика по отношению к системе образования ведется, как и в случае со студентами-социологами и регионоведами, через апелляцию к ценностям индустриального града с акцентированием общего тренда несоответствия преподаваемого материала актуальным требованиям рынка труда.

\begin{abstract}
«Вот я поступил на программу “прикладная математика”, но хочу быть программистом. И я понимаю, что тут как таковых знаний мне просто не дадут так, чтобы я вышел из университета и сразу пошел на работу. Требуется самому что-то выучить. А тут базу дают, учат думать» (студент-кибернетик).

«В университете дают то, что полезно на работе... как бы... Здесь дают очень хорошую математическую базу, которая не во всех IT-сферах будет полезна, но в некоторых все же будет. И, в принцие, да, нас учат, и да, надо учиться самому. IT-сфера быстро развивается, а преподаватели не успевают за этим» (студент-кибернетик).
\end{abstract}

Что же в таком случае является причиной, блокирующей перевод критики с локального уровня на публичный? Непосредственно из полученных данных сделать обоснованный вывод не представляется возможным, но по совокупности косвенных факторов можно сформулировать предположения, составляющие каркас объяснительной схемы. Эти предположения дополняют выделенные идеальные типы и могут служить гипотезами в будущих исследованиях причин студенческого недовольства.

Во-первых, решение проблемы рассогласования между актуальными требованиями рынка и образовательной программой отдается на откуп самого студента. Внесение изменений в учебном плане сопряжено с рядом бюрократических проволочек, что затягивает время интеграции новой информации в системы обучения. Кроме того, профессорско-преподавательский состав университетов далеко не всегда связан с работой над рыночно-ориентированными проектами, поэтому бывает далек от текущих трендов в индустрии.

Во-вторых, согласуясь с метафорой «области насыщенности смыслов», можно сделать предположение, что студенты, хорошо представляющие себе совокупность релевантных для рынка навыков и знаний, могут эффективно использовать сторонние образовательные ресурсы (например, онлайн-курсы по своей специализации). Требования рынка ИТ к специалистам выражены предельно четко: достаточно набрать в любом интернет-агрегаторе вакансий ${ }^{20}$ запрос «программист», и мы увидим, что в графе «требуемые навыки» указывается ограниченный перечень языков программирования. Учебные пособия и онлайн-платформы также находятся в свободном доступе, что сильно облегчает процесс пополнения знаний, которых не хватает в рамках университетской программы.

Таким образом, мы можем предположить, что основной причиной отсутствия публичных споров по поводу качества высшего образования в среде технических специалистов (в частности, тех, кто намерен связать свою будущую деятельность с IT-сферой) является наличие относительно беспроблемного альтернативного способа получения навыков. Такая ситуация позволяет критике

20 В качестве примера мы использовали ресурс hh.ru. 
существовать в формате частных обсуждений, и необходимость во взаимной координации действий отпадает сама собой: спасение утопающих - дело рук самих утопающих, особенно когда рядом с тобой плавает спасательный круг. В свою очередь, обучение в университете сохраняет за собой смысл с точки зрения престижа, то есть отсылает к миру величия в терминах французской прагматической социологии.

\section{Заключение}

Проблема удовлетворенности студентов существовала всегда, но в эпоху академического капитализма ее актуальность выходит на новый уровень. Причина этого кроется в том, что, если университет перестраивается на рыночные рельсы и его эффективность оценивается в терминах рыночной эффективности, рано или поздно критика со стороны студента должна быть воспринята в том же ключе, как и критика продукта компании со стороны целевой аудитории или даже критика профсоюзов относительно условий организации труда. В этой связи нашей целью стала попытка ответить на вопросы: почему при наличии объективных поводов к недовольству студенты не выносят критику на публичный уровень; почему, собственно, целевая аудитория в большинстве случаев остается безмолвной?

Для ответа на поставленные вопросы мы обратились к теоретическим положениям французской прагматической социологии и представили университет как организацию, конституированную моральными конвенциями между ее членами, коими и являются студенты. Мы попытались выявить ценностные основания критических аргументов, высказываемых студентами, а также ограничения на пути перевода критики в публичное поле. В результате, как мы и ожидали, в ситуациях недовольства студенты чаще апеллируют к миру ценностей индустриального града справедливости, в рамках которого превыше всех ценятся техническая эффективность, слаженность процессов и четкость. Основной мотив критики - это рассогласование между получаемым образованием и ожиданиями рынка труда. В целом это вполне ожидаемый вывод, учитывая тенденции отставания вузов от требований потенциальных работодателей [Константиноский, Попова 2015; Танова, Евсеева, Поздеева, Тростинская 2018, с. 97]. Однако гораздо больший интерес вызывают мотивы, блокирующие артикуляцию критики через выборные органы (студсоветы, профсоюзы) или иные механизмы вывода на публичный уровень.

На основании собранных данных мы выделяем два «идеальных» типа скрытого студенческого недовольства, принимающего сходные формы, однако сильно различающиеся по своей внутренней логике в зависимости от специальности.

Студенты социально-гуманитарного профиля, представленного в нашем случае специализациями «социология» и «зарубежное регионоведение» российских и украинского вузов, обладают низкой степенью осведомленности о том, какое место они могут занять на рынке труда, что вызывает затруднения в оценке содержания учебных программ. Критические суждения здесь отличаются требованием большей практико-ориентированности преподаваемых дисциплин, более ясного изложения материала. При этом студенты, не имея четких представлений о том, какие навыки 
и знания из учебного плана могут оказаться полезными в поисках работы, не могут сформировать четких требований к администрации, что пресекает возможность публичных дебатов. Этот формат назван нами «туман войны». Можно предположить, что снизить градус неопределенности могло бы тесное сотрудничество с компаниями реального сектора, в которых востребованы навыки выпускников, однако это возможно не для всех специальностей и не для каждого региона. Так, например, в Департаменте социологии московского кампуса НИУ ВШЭ действуют три базовые кафедры потенциальных работодателей для выпускников: (1) базовая кафедра ГФК-Русь; (2) базовая кафедра Фонда «Общественное мнение»; (3) базовая кафедра Всероссийского центра изучения общественного мнения (ВЦИОМ). Однако в других городах страны подобного рода перспективы осложняются гораздо меньшим спросом на услуги специалистов по прикладным исследованиям.

Случай студентов технического профиля, наоборот, отличается предельно понятными перспективами на рынке труда. Их критика сосредоточена на моральном отставании содержания образовательных программ от актуальных требований рынка. Тем не менее, в отличие от будущих социологов и регионоведов, студенты технических профилей могут ориентироваться на конкретные требования рынка труда, предъявляемые к представителям их профессии. Для них не составляет труда определить и осваивать релевантные знания целенаправленно в обход морально устаревших учебных программ. Обучение в университете начинает (или продолжает) расцениваться в качестве средства повышения престижа, но не как основная площадка для получения знаний. Таким образом, организационный компромисс отсутствия публичного выражения недовольства в рассмотренных нами вузах обусловлен неравномерным распределением знания о том, что представляет собой осваиваемая профессия. Студенты социально-гуманитарного профиля находятся в ситуации практически полной неопределенности относительно релевантности получаемых знаний и навыков на рынке труда, а студенты технической специализации, наоборот, имеют полное или близкое к тому представление о перспективах и особенностях трудоустройства за пределами академии.

Проведенный нами анализ не претендует на полноту, но тем не менее представляется, что полученные выводы позволяют двигаться дальше и могут стать основой для более детального сравнительного исследования. Кроме того, в силу ограничения доступной базы данных требует уточнения ряд важных вопросов, как то: что говорят о качестве образования студенты социально-гуманитарных профилей, у которых в силу обстоятельств рано сложилась профессиональная идентичность; возможно, они и пытаются переводить критику в публичный формат, но в силу меньшинства, режима ограниченного доступа или особенностей бюрократизации их начинания не имеют эффекта? Все эти темы важны для понимания как общего характера функционирования академии в условиях академического капитализма, так и его региональных версий.

\section{Литература}

Абрамов Р.Н. (2011) Менеджериализм и академическая профессия. Конфликт и взаимодействие // Социологические исследования. № 7. С. 37-47. 
Абрамов Р.Н., Груздев И.А., Терентьев Е.А. (2016) Академическая профессия и идеология «медленной науки» // Высшее образование в России. № 10. С. 62-70.

Болтански Л., Тевено Л. (2013) Критика и обоснование справедливости: Очерки социологии градов. М.: Новое литературное обозрение.

Вебер М. (1990) «Объективность» социально-научного и социально-политического познания // Вебер М. Избранные произведения. М.: Прогресс. С. 345-415.

Гилл Р. (2014) Прервать молчание. Скрытые травмы неолиберальной академии // Социальный компас. 14 февраля 2014 // http:/www.socialcompas.com/2014/02/14/ prervat-molchanie-skry-ty-e-travmy-neoliberal-noj-akademii/

Гимпельсон В., Капелюшников Р., Рощин С. (2017) Российский рынок труда: тенденции, институты, структурные изменения. Доклад Центра трудовых исследований и Лаборатории исследований рынка труда НИУ ВШЭ // http://csr.ru/wp-content/uploads/2017/03/Doklad_trud.pdf

Двенадцать решений для нового образования. Доклад центра стратегических разработок и высшей школы экономики. (2018). М.: ВШЭ // https://www.hse.ru/data/2018/04/06/1164671180/Doklad obrazovanie Web.pdf

Димаджио П., Пауэлл У. (2010) Новый взгляд на «железную клетку»: институциональный изоморфизм и коллективная рациональность в организационных полях // Экономическая социология. Т. 11. № 1. С. 34-56.

Клаузевиц К. (2009) О войне. М.: Римис.

Ковенева О.В. (2008) Французская прагматическая социология: от модели «градов» к теории «множественных режимов вовлеченности» // Социологический журнал. № 1. С. 5-21.

Константиновский Д.Л., Попова Е.С. (2015) Молодежь, рынок труда и экспансия высшего образования // Социологические исследования. № 11. С. 37-48.

Константиновский Д.Л., Попова Е.С. (2016) Отношение молодежи к образованию в современной России // Общественные науки и современность. № 1. С. 5-19.

Малик В.М., Куракин Д.Ю., Павленко Е.С. (2018) Типичные образовательно-трудовые траектории и мотивы студентов сельских профессиональных образовательных организаций // Мониторинг экономики образования. № 10(76). М.: ВШЭ.

Нефедова А.И. (2015) О концептах «академического капитализма» и «предпринимательского университета» // Высшее образование в России. № 6. С. 75-81.

Соколов М.М. (2017) Миф об университетской стратегии. Экономические ниши и организационные карьеры российских вузов // Вопросы образования. № 2. С. 36-73.

Стариков В.С. (2016) Качественный сравнительный анализ трансформаций вузов: от советского классического к постсоветскому исследовательскому университету // Социология науки и технологий. № 2. С. 134-143.

Старыгина A.M. (2016) Концептуальные подходы к исследованию системы образования в контексте социальных трансформаций современности // Гуманитарий Юга России. T. 19. № 3. C. 155-163.

Страусс А., Корбин Д. (2001) Основы качественного исследования: обоснованная теория. Процедуры и техники. М.: УРСС.

Танова А.Г., Евсеева Л.И., Поздеева Е.Г., Тростинская И.Р. (2018) Субъектные аспекты мониторинга удовлетворенности студентов качеством образования (по материалам Центра социологических исследований СПбПУ) // Научно-технические ведомости СПбГПУ. Гуманитарные и общественные науки. Т. 9. № 1. С. 90-101.

Тевено Л. (2002) Организованная комплексность: конвергенции координации и композиция экономических образований // Радаев В.В. (ред.) Экономическая социология: новые подходы к институциональному и сетевому анализу. М.: РОССПЭН. С. 19-44.

Тевено Л. (2006) Креативные конфигурации в гуманитарных науках и фигурации социальной общности // Новое литературное обозрение. № 1(77) // https://magazines.gorky.media/nlo/2006/1/kreativnye-konfiguraczii-v-gumanitarnyhnaukah-i-figuraczii-soczialnoj-obshhnosti.html

Тевено Л. (2009) Ценности, координация и рациональность: экономика соглашений или эпоха сближения экономических, социальных и политических наук // Олейник А. (ред.) Институциональная экономика: учебник. РЭА им. Г.В. Плеханова. М.: Инфра-М. С. 76-112. 
Трегубова Н.Д., Стариков В.С. (2017) Образовательная миграция и этносоциальные конфликты в вузах России, Украины и США // Мониторинг общественного мнения: Экономические и социальные перемены. № 1. С. 121-139.

Филиппов А.Ф. (2012) «Прямая речь: Александр Филиппов» // Postnauka.ru. 7 июня 2012 // https://postnauka.ru/talks/399

Фуллер С. (2018) Социология интеллектуальной жизни: карьера ума внутри и вне академии. М.: Дело.

Шнедельбах Г. (2002) Университет Гумбольдта // Логос. № 5-6(35). С. 1-14.

Furedi F. (2011) Introduction to the Marketisation of Higher Education and the Student as Consumer // The Marketisation of Higher Education and the Student as Consumer (eds. Molesworth M., Scullion R., Nixon E.), London: Routledge, pp. 1-7.

Graeber D. (2012) Dead Zones of the Imagination. On Violence, Bureaucracy, and Interpretive Labor // Journal of Ethnographic Theory, no 2, pp. 105-128.

Hess D. (2007) Alternative Pathways in Science and Industry, Cambridge, MA: MIT Press.

Hirt C., Wong K., Erichsen C., White J.S. (2013) Medical Dramas on Television: A Brief Guide for Educators // Medical Teacher, vol. 35, no 3, pp. 237-242.

Lynch M. (2002) The Living Text: Written Instructions and Situated Actions in Telephone Surveys // In Standardization and Tacit Knowledge: Interaction and Practice in the Survey Interview (eds. Maynard D., Houtkoop-Steenstra H., Schaeffer N., van der Zouwen J.), New York: John Wiley, pp. 125-150.

Maringe F. (2011) The Student as Consumer: Affordances and Constraints in a Transforming Higher Education Environment // The Marketisation of Higher Education and the Student as Consumer (eds. Molesworth M., Scullion R., Nixon E.), London: Routledge, pp. 142-155.

Powell W., Snellman K. (2004) The Knowledge Economy // Annual Review of Sociology, no 30, pp. 99-220.

Slaughter S., Leslie L. (1997) Academic Capitalism: Politics, Policies and the Entrepreneurial University, Johns Hopkins UP.

Stehr N. (2002) Knowledge and Economic Conduct: The Social Foundations of the Modern Economy, University of Toronto Press, Scholarly Publishing Division.

Tight M. (2013) Students: Customers, Clients or Pawns? // Higher Education Policy, no 26, pp. 291-307.

\title{
Latent Student Discontent under Academic Capitalism: A Comparative Analysis of Ideal Types of Students in Natural and Social Sciences Departments
}

\author{
A. REZAEV*, M. NI**
}

*Andrey Rezaev - DSc in Philosophy, Head of Chair of Comparative Sociology, Saint Petersburg State University. Address: 7-9, Universitetskaya Emb., Saint Petersburg, 199034, Russian Federation. E-mail: rezaev@hotmail.com

**Maxim Ni - PhD Student, Chair of Comparative Sociology, Saint Petersburg State University. Address: 7-9, Universitetskaya Emb., Saint Petersburg, 199034, Russian Federation. E-mail: jintae@mail.ru

Citation: Rezaev A., Ni M. (2020) Latent Student Discontent under Academic Capitalism: A Comparative Analysis of Ideal Types of Students in Natural and Social Sciences Departments. Mir Rossii, vol. 29, no 2, pp. $49-71$ (in Russian). DOI: $10.17323 / 1811-038 X-2020-29-2-49-71$ 


\section{Abstract}

This paper develops and tests conceptual tools for studying hidden causes (i.e. those not presented in the public space) of the university student discontent under academic capitalism. Accounting for latent student discontent is important for understanding current managerial practices in higher education. While academic capitalism presumes an orientation to the needs of the students, it also presumes the need to orient university education towards the requirements of the labor market. Empirically the study draws on interviews and focus groups with students and lecturers in three large universities in Russia and Ukraine. The theoretical framework of the study is based on French pragmatic sociology, in which a university is considered an organization constituted by moral conventions between its members. The authors reveal the critical arguments which students articulate regarding their education as well as two ideal types of latent student discontent that characterize those who are enrolled in natural and social sciences. Social science students experience uncertainty regarding the relevance of their skills and knowledge for the labor market. They are also unable to convey clear requirements to their university. On the contrary, STEM students have a clear idea regarding their future jobs. These ideal types constitute the basis of the research hypotheses, which can be further examined in the context of post-Soviet higher education systems development.

Key words: university, academic capitalism, dissatisfaction, students, labor market, cities of justification

\section{References}

Abramov R.N. (2011) Menedzherializm i akademicheskaya professiya. Konflikt i vzaimodejstvie [Managerialism and Academic Profession. Conflict and Interaction]. Sotsiologicheskie issledovaniya, no 7, pp. 37-47.

Abramov R.N., Gruzdev I.A., Terent'ev E.A. (2016) Akademicheskaya professiya i ideologiya «medlennoj nauki» [Academic Profession and Ideology of "Slow Scholarship"]. Vysshee obrazovanie v Rossii, no 10, pp. 62-70.

Boltanski L., Teveno L. (2013) Kritika i obosnovanie spravedlivosti: Ocherki sotsiologii gradov [Critique and Justification of Justice: Essays on the Sociology of Worlds], Moscow: Novoe literaturnoe obozrenie.

DiMaggio P., Powell W. (2010) Novyj vzglyad na «zheleznuyu kletku»: institutsional'nyy izomorfizm i kollek-tivnaya ratsional'nost' $\mathrm{v}$ organizatsionnykh polyakh [The Iron Cage Revisited: Institutional Isomorphism and Collective Rationality in Organizational Fields]. Ekonomicheskaya sotsiologiya, vol. 11, no 1, pp. 34-56. Available at: https://ecsoc.hse.ru/2010-11-1/26595675.html, accessed 20.02.2020.

Dvenadtsat' reshenij dlya novogo obrazovaniya. Doklad Tsentra strategicheskikh razrabotok $i$ Vysshej shkoly ekonomiki [Twelve Decisions for New Education. Report of the Center of Strategic Development and Higher School of Economics] (2018), Moscow: HSE. Available at: https://www.hse.ru/data/2018/04/06/1164671180/Doklad_obrazovanie_Web.pdf, accessed 20.02.2020.

Filippov A.F. (2012) «Pryamaya rech’: Aleksandr Filippov» [Direct Speech: Alexander Fillipov]. Postnauka.ru, June 7, 2012. Avalible at: https://postnauka.ru/talks/399, accessed 20.02.2020. 
Fuller S. (2018) Sotsiologiya intellektual'noj zhizni: kar'era uma vnutri i vne akademii [Sociology of Intellectual Life: The Career of the Mind In and Around the Academy], Moscow: Delo.

Furedi F. (2011) Introduction to the Marketisation of Higher Education and the Student as Consumer. The Marketisation of Higher Education and the Student as Consumer (eds. Molesworth M., Scullion R., Nixon E.), London: Routledge, pp. 1-7.

Gill R. (2014) Prervat' molchanie. Skrytye travmy neoliberal'noj akademii [Breaking the Silence: The Hidden Traumas of Neo-liberal Academia]. Social Compass, February 14, 2014. Available at: http://www.socialcompas.com/2014/02/14/prervat-molchanie-skry-ty-etravmy-neoliberal-noj-akademii/, accessed 20.02.2020.

Gimpel'son V., Kapelyushnikov R., Roshchin S. (2017) Rossijskij rynok truda: tendentsii, instituty, strukturnye izmeneniya. Doklad Tsentra trudovykh issledovanij $i$ Laboratorii issledovanij rynka truda NIU VShE [Russian Labor Market: Trends, Institutions, Structural Changes. Report by the Labor Research Center and Labor Market Research Laboratory of the National Research University Higher School of Economics]. Available at: http://csr.ru/wp-content/uploads/2017/03/Doklad trud.pdf, accessed 20.02.2020.

Graeber D. (2012) Dead Zones of the Imagination. Ōn Violence, Bureaucracy, and Interpretive Labor. Journal of Ethnographic Theory, no 2, pp. 105-128.

Hess D. (2007) Alternative Pathways in Science and Industry, Cambridge, MA: MIT Press.

Hirt C., Wong K., Erichsen C., White J.S. (2013) Medical Dramas on Television: A Brief Guide for Educators. Medical Teacher, vol. 35, no 3, pp. 237-242.

Konstantinovskij D.L., Popova E.S. (2015) Molodezh', rynok truda i ekspansiya vysshego obrazovaniya [The Youth, the Labor Market and the Expansion of Higher Education]. Sotsiologicheskie issledovaniya, no 11, pp. 37-48.

Konstantinovskij D.L., Popova E.S. (2016) Otnoshenie molodezhi k obrazovaniyu v sovremennoj Rossii [Youth Attitudes towards Education in Modern Russia]. Obshchestvennye nauki i sovremennost', no 1, pp. 5-19.

Koveneva O.V. (2008) Frantsuzskaya pragmaticheskaya sotsiologiya: ot modeli «gradov» k teorii «mnozhestvennykh rezhimov vovlechennosti» [French Pragmatic Sociology: from the Model of "Cities" towards the Theory of "Multiple Modes of Inclusion"]. Sotsiologicheskij zhurnal, no 1, pp. 5-21.

Lynch M. (2002) The Living Text: Written Instructions and Situated Actions in Telephone Surveys. In Standardization and Tacit Knowledge: Interaction and Practice in the Survey Interview (eds. Maynard D., Houtkoop-Steenstra H., Schaeffer N., van der Zouwen J.), New York: John Wiley, pp. 125-150.

Malik V.M., Kurakin D.Yu., Pavlenko E.S. (2018) Tipichnye obrazovatel'no-trudovye traektorii i motivy studentov sel'skikh professional'nykh obrazovatel'nykh organizatsij [The Typical Educational and Labor Trajectories and the Motives of Students of Rural Professional Education Schools]. Monitoring ekonomiki obrazovaniya, no 10(76), Moscow: HSE.

Maringe F. (2011) The Student as Consumer: Affordances and Constraints in a Transforming Higher Education Environment. The Marketisation of Higher Education and the Student as Consumer (eds. Molesworth M., Scullion R., Nixon E.), London: Routledge, pp. 142-155.

Nefedova A.I. (2015) O kontseptakh «akademicheskogo kapitalizma» i «predprinimatel'skogo universiteta» [On the Concepts of "Academic Capitalism" and "Entrepreneurship University"]. Vysshee obrazovanie v Rossii, no 6, pp. 75-81.

Powell W., Snellman K. (2004) The Knowledge Economy. Annual Review of Sociology, no 30, pp. 99-220.

Schnädelbach H. (2002) Universitet Gumbol'dta [Humboldt University]. Logos, no 5-6(35), pp. 1-14.

Slaughter S., Leslie L. (1997) Academic Capitalism: Politics, Policies and the Entrepreneurial University, Johns Hopkins UP.

Sokolov M.M. (2017) Mif o strategii universiteta. Ekonomicheskie nishi i organizatsionnaya kar'yera rossijskikh vuzov [The Myth of the University Strategy. Economic Niches and Organizational Careers in Russian Universities]. Voprosy obrazovaniya, no 2, pp. 36-73.

Starikov V.S. (2016) Kachestvennyj sravnitel'nyj analiz transformatsij vuzov: ot sovetskogo klassicheskogo k postsovetskomu issledovatel'skomu universitetu [Qualitative Comparative Analysis of HEIs' Transformation: From Soviet Classical to Post-Soviet Research University]. Sotsiologiya nauki i tekhnologij, no 2, pp. 134-143. 
Starygina A.M. (2016) Kontseptual'nye podkhody $\mathrm{k}$ issledovaniyu sistemy obrazovaniya V kontekste sotsial'nykh transformatsij sovremennosti [Conceptual Approaches to the Study of the Educational System in the Context of Social Transformation]. Gumanitarij Yuga Rossii, vol. 19, no 3, pp. 155-163.

Stehr N. (2002) Knowledge and Economic Conduct: The Social Foundations of the Modern Economy, University of Toronto Press, Scholarly Publishing Division.

Strauss A., Korbin D. (2001) Osnovy kachestvennogo issledovaniya: obosnovannaya teoriya. Protsedury $i$ tekhniki [Basics of Qualitative Research: Grounded Theory Procedures and Techniques], Moscow: URSS.

Tanova A.G., Evseeva L.I., Pozdeeva E.G., Trostinskaya I.R. (2018) Sub'ektnye aspekty monitoringa udovletvorennosti studentov kachestvom obrazovaniya (po materialam Tsentra sotsiologicheskikh issledovanij SPbPU) [Subjective Aspects of Monitoring the Quality of Educational Services (based on the Materials of the SPbU Center for Sociological Research)]. Nauchno-tekhnicheskie vedomosti SPbGPU. Gumanitarnye i obshchestvennye nauki, vol. 9, no 1, pp. 90-101.

Teveno L. (2002) Organizovannaya kompleksnost': konvergentsii koordinatsii i kompozitsiya ekonomicheskikh obrazovanij [Organized Complexity: Conventions of Coordination and the Composition of Economic Arrangements]. Ekonomicheskaya sotsiologiya: novye podkhody k institutsional'nomu i setevomu analizu [Economic Sociology: New Approaches to Institutional and Network Analysis] (ed. Radaev V.V.), Moscow: ROSSPEN. pp. 19-44.

Teveno L. (2006) Kreativnye konfiguratsii v gumanitarnykh naukakh i figuratsii sotsial'noj obshchnosti [Creative Configurations in the Humanities and Social Communality Figurations]. Novoe literaturnoe obozrenie, no 1(77). Available at: https://magazines.gorky.media/nlo/2006/1/kreativnye-konfiguraczii-v-gumanitarnyhnaukah-i-figuraczii-soczialnoj-obshhnosti.html, accessed 20.02.2020.

Teveno L. (2009) Tsennosti, koordinatsiya i ratsional'nost': ekonomika soglashenij ili epokha sblizheniya ekonomicheskikh, sotsial'nykh i politicheskikh nauk [Values, Coordination and Rationality: the Economics of Agreements or an Era of Convergence between the Economic, Social and Political Sciences]. Institutsional'naya ekonomika [Institutional Economics] (ed. Olejnik A.), Moscow: Infra-M, pp. 76-112.

Tight M. (2013) Students: Customers, Clients or Pawns? Higher Education Policy, no 26, pp. 291-307.

Tregubova N.D., Starikov V.S. (2017) Obrazovatel'naya migratsiya i etnosotsial'nye konflikty v vuzakh Rossii, Ukrainy i SShA [Educational Migration and Ethno-social Conflicts in Higher Education Institutions in Russia, Ukraine and the USA.] Monitoring obshchestvennogo mneniya: Ekonomicheskie i sotsial'nye peremeny, no 1, pp. 121-139.

von Clausewitz C. (2009) $O$ voine [On War], Moscow: Rimis.

Weber M. (1990) “Obiektivnost' sotsial'no-nauchnogo i sotsial'no-politicheskogo poznaniya [The "Objectivity" of Social-Scientific and Social-Political Cognition]. Weber M. Izbrannye proizvedeniya, Moscow: Progress, pp. 345-415. 